\title{
POTENCY AND EFFICACY TEST OF A VACCINE IN ADDITION WITH ADJUVANT AGAINST KOI HERPESVIRUS IN KOI (Cyprinus carpio)
}

\author{
Lili Sholichah"*\#, Munti Yuhana*), Angela Mariana Lusiastuti**), and Tri Heru Prihadi ${ }^{* * *}$ \\ " Graduate School of Aquaculture Science, Bogor Agricultural University, Indonesia \\ *) Department of Aquaculture, Faculty of Fisheries and Marine Science, Bogor Agricultural University, Indonesia \\ **) Research and Development Institute for Freshwater Aquaculture, Indonesia
}

\begin{abstract}
Koi Herpesvirus (KHV) is a malignant virus infecting the goldfish and koi in all stadia and cause mortality up to $95 \%$ The purpose of this study was to determine the potency and efficacy of inactivated-vaccine in addition with adjuvant against KHV in koi fish. The viral propagation was done using a KF-1 cell line in 25 $\mathrm{cm}^{2}$ flask. The cultured virus was harvested on 12 days post inoculation, and then the harvested virus was inactivated with $0.1 \%$ formal in as inactivated-vaccine. Three hundred of test fish $(10.38 \pm 1.25 \mathrm{~g})$ maintained in $126 \mathrm{~L}$ of plastic containers with aeration, and fed with pellets twice a day. After 14 days of adaptation, the fish were divided into five treatments $(A=$ vaccine; $B=$ vaccine + Complete Freund's Adjuvant; $C=$ vaccine + Incomplete Freund's Adjuvant; $\mathrm{K}+=$ = positive control, and $\mathrm{K}-=$ negative control) and each treatment has four replicates. Vaccine was given by injecting intramuscularly of $0.1 \mathrm{~mL}$ per fish. All fish were challenged by injecting intramuscularly of $0.1 \mathrm{~mL}$ of KHV virus with concentration of $10^{4.58} \mathrm{TCID}_{50} / \mathrm{mL}$ after 21 days post vaccination. The results showed that the $B$ treatment had higher $(P<0.05)$ values of hematocrit level, lysozyme activity, and titer of antibody compared with positive control. In addition, the survival of fish in $\mathrm{B}$ treatment also had the highest percentages and significantly different compared to other treatments $(\mathrm{P}<0.05)$. The conclusion of this research was the application of inactivated $\mathrm{KHV}$ vaccine in $0.1 \%$ formalin with the addition of Complete Freund's Adjuvant through the injection dose $0.1 \mathrm{~mL}$ fish $^{-1}$ in $10^{4.58} \mathrm{TCID}_{50} / \mathrm{mL}$ capable to enhance the immune responses and raised the optimal protection of KHV antibody in koi fish.
\end{abstract}

KEYWORDS: inactivated vaccines; adjuvants; immune responses; Cyprinus carpio; KHV

\section{INTRODUCTION}

Koi Herpesvirus Disease (KHV/KHVD) is a virus that causes the contagious disease in koi and goldfish (Ilouze et al., 2006). KHVD was first reported in Israel and the United States in 1998. Furthermore, the disease spread to other countries such as Poland, UK, Germany, and the Netherlands (Antychowicz et al., 2005). In Asia, KHVD outbreak was first reported in Indonesia in April 2002 (Melba, 2004).

Fish infected with KHV showed pale white and necrosis in the gill filaments. Other clinical symptoms may include abnormal eye, pale body surface, mucus production, and pale spots on the skin. KHV outbreaks in some cases showed no clinical symptoms (Lio-Po, 2011). This virus can infect goldfish when the water

\# Correspondence: Graduate School of Aquaculture Science, Bogor Agricultural University. Jl. Lingkar Akademik, Kampus IPB Dramaga, Bogor 16680, Indonesia. Phone: + (0251) 8621210 E-mail: lili.bihatdepok@gmail.com temperature ranging from $17^{\circ} \mathrm{C}-27^{\circ} \mathrm{C}$ whereas high virulence occurs at a temperature of $22^{\circ} \mathrm{C}-24^{\circ} \mathrm{C}$ (Perelberg et al., 2003). Deaths caused by KHV may reach $80 \% 95 \%$ (Sunarto et al., 2005).

Several kinds of vaccines used in fish farming, among others; whole-cell vaccines, vaccines from cell components, and DNA vaccines. The viral vaccine is an antigen preparation derived from attenuated or killed. Yasumoto et al. (2006) in Japan developed a formalin-inactivated vaccine KHV by utilizing liposomal membrane applied to the fish feed.

Nakajima et al. (1999) using iridovirus vaccine from GF cell (grunt fin) on red sea bream (Pagrus major) which was formalin inactivated for 12 days at $4^{\circ} \mathrm{C}$ and obtain $72 \%$ of relative percent survival (RPS). The type of adjuvant used is Complete Freund's Adjuvant (CFA) and Incomplete Freund's Adjuvant (IFA). According to Aucouturier et al. (2001), IFA is a water in oil (W/O) emulsion, which is able to improve and stabilize the 
antibody titer. The purpose of this study was to determine the potency and efficacy of inactivated vaccine against KHV combine with adjuvant which produced from KF-1 cell cultures.

\section{MATERIALS AND METHODS}

\section{Procurement Fish and Virus Isolates}

Three hundred of koi fish (Cyprinus carpio) used in this study (average weight of $10.38 \pm 1.25 \mathrm{~g}$ ) were obtained from a private farm in Sukabumi, West Java which provides the SPF (Specific Pathogen Free) KHV through previous PCR test. Virus strain was namely BJMN-2, which was a collection of Research Station for Fish Disease Control, Depok, Indonesia.

\section{Cell Culture and KHV Virus}

KF-1 cells were used in this study. KF-1 cells were grown in T-flasks at $25^{\circ} \mathrm{C}$ to confluence in Leibovitz's media (L-15 : Gibco) supplemented with 20\%FBS (Fetal Bovine Serum : Gibco). The monolayers of KF-1 cells were inoculated with KHV inoculum then supplemented with $2 \% \mathrm{FBS}$, respectively. Infected cells were incubated at $25^{\circ} \mathrm{C}$. Cytopathic effect (CPE) was daily observed under a light microscopy.

The viral cultured was harvested when cytopathic effect (CPE) had reached $\pm 80 \%$ Supernatant was taken and stored at $-80^{\circ} \mathrm{C}$ until ready to use and mostly used for the measurement of $\mathrm{TCID}_{50^{\circ}}$

\section{TCID $_{50}$}

Determination of tissue culture infective dose $\left(T C I D_{50}\right)$ was performed to quantify how much infectious virus was in a vaccine preparation. $\mathrm{TCID}_{50} \mathrm{Cal}$ culation was based on the method of Reed $\&$ Muench (1938):

$$
\mathrm{TCID}_{50}=\left(\frac{50 \%-\mathrm{a}}{\mathrm{b}-\mathrm{a}}\right)
$$

Where: $a=\%$ ositive at dilution below $50 \%$ $b=\%$ positive at dilution above $50 \%$

\section{Production of Vaccines}

The harvested virus was inactivated refers to Yasumoto et al. (2006) with minor modifications. Unlike what did Yasumoto in common carp (Cyprinus carpio) where the KHV vaccines produced from KF-1 cell is inactivated with $0.3 \%$ formalin and stored for 48 hours at a temperature of $24^{\circ} \mathrm{C}$ before use.

The vaccine in this study are inactivated with formalin $0.1 \%$ of the KHV virus then filtered using a 450 $\mathrm{nm}$ millipore and directly used for the test.
Adjuvants was substances added to vaccines to stimulate the immune response. Differences between CFA and IFA contained in the composition of the constituent material which was in $1 \mathrm{~mL}$ CFA consisted of $1 \mathrm{mg}$ of Mycobacterium tuberculosis in the form of heat-killed/dried; $0.85 \mathrm{~mL}$ of paraffin oil; and $0.15 \mathrm{~mL}$ mannide monooleate. However $M$. tuberculosis not contained in the IFA.

The comparison between either complete or incomplete adjuvant and vaccine solution were 0.25 / $0.75(\mathrm{v} / \mathrm{v})$. The composition of adjuvant and vaccine was obtained from Agar Gel Precipitation Test (AGPT) which carried out previously.

\section{Vaccination}

Vaccination was performed by the method of intramuscularly injection with a volume of $0.1 \mathrm{~mL} /$ fish. The experimental design was Completely Randomized Design with five treatments and four replications as follows: treatment $A$ : vaccines; treatment $B$ : vaccine + Complete Freund's Adjuvant; treatment $C$ : vaccine + Incomplete Freund's Adjuvant; $\mathrm{K}+$ : positive control (injected with PBS, tested challenged); K-: negative control (injected with PBS, challenged not tested).

Fish were reared in plastic container sized $60 \mathrm{~cm}$ x $70 \mathrm{~cm} \times 40 \mathrm{~cm}$ with stocking density of 15 fish container $^{-1}$. Water temperature was range at $24^{\circ} \mathrm{C}$ $25^{\circ} \mathrm{C}$ and fed with a pellet twice a day at satiation. The fourth replications in each treatment used for blood and serum sampling.

\section{Challenge Test}

Challenge test was performed on day 21 after vaccination and maintenance carried out for 14 days post challenge test. The fish were injected intramuscularly with $0.1 \mathrm{~mL}$ of virus inucula/fish. Virus was diluted up to 100 times $\left(10^{-2}\right)$ of $\mathrm{TCID}_{50} / \mathrm{mL}$ have been done previously. $\operatorname{TCID}_{50}$ already used to obtain Lethal Dose $50\left(L_{50}\right)$ from the Koch's postulates. Koch postulate test was done with serial dilutions using $\mathrm{TCID}_{50}$ dose without dilution, $\mathrm{TCID}_{50}$ dilution 10 times, $\mathrm{TCID}_{50}$ dilution 100 times, $\mathrm{TCID}_{50}$ dilution 1,000 times and $\mathrm{TCID}_{50}$ dilution 10,000 times. Koch's postulates test showed that the $\mathrm{LD}_{50}$ was obtained on $\mathrm{TCID}_{50}$ dilution 100 times. Dose of 100 times of virus dilution then was used for a challenge test by injecting $0.1 \mathrm{~mL}$ each fish.

\section{Measurement of Immunological Parameters}

Measurement parameters of the immunological system consists of antibody titer by ELISA, hematocrit, and lysozyme activity. 
Preparation of antigen for the ELISA test conducted prior to the KHV virus purification process according to Ronen et al. (2003). Purified protein of $\mathrm{KHV}$ antigen was measured by the method of Bradford. Antigen was coated $10 \mathrm{ug} / \mathrm{mL}$ in each well and incubated at $4^{\circ} \mathrm{C}$ overnight. Directly plate was blocked using $200 \mu \mathrm{L}$ of PBS-BSA $1 \%$ and incubated at $22^{\circ} \mathrm{C}$ for one hour. Plate was washed three times with $400 \mu \mathrm{L}$ of PBS-T. Serum samples were then added to each well of $200 \mu \mathrm{L}$ (Duplo) and incubated at a temperature of $22^{\circ} \mathrm{C}$ for three hours. Plate was washed three times with $400 \mu \mathrm{L}$ of PBS-T. Koi carp (Cyprinus carpio) IgM monoclonal antibody (AQUATIC Diagnostics Ltd.) added about $100 \mu \mathrm{L}$ in each well and incubated at $22^{\circ} \mathrm{C}$ for one hour. Plate was washed three times with $400 \mu \mathrm{L}$ of PBS-T. Anti-mouse IgG-peroxidase antibody produced in rabbit (SIGMA-ALDRICH) was added to each well of $100 \mu \mathrm{L}$ and incubated at $22^{\circ} \mathrm{C}$ for one hour. Plate was washed three times with $400 \mu \mathrm{L}$ of PBS-T. One-Step UItra TMB-ELISA was further added to each well of $100 \mu \mathrm{L}$ and let stand for 10 minutes. The reaction was stopped by adding $50 \mu \mathrm{L} \mathrm{H}_{2} \mathrm{SO}_{4} 2 \mathrm{M}$ and do the reading optical density (OD) at $450 \mathrm{~nm}$. The cut of value (CV) in this test was obtained by the equation:

$$
\mathrm{CV}=\begin{gathered}
\text { Mean negative control }+(2 \times \text { standard } \\
\text { deviation })
\end{gathered}
$$

Hematocrit measurement is done by comparing a part of blood that settles (a) to all parts of the blood contained in the microhematocrit tube (b), hematocrit levels expressed as \%volume solid blood cells were calculated by using the equation of:

$$
\mathrm{He}=\frac{\mathrm{a}}{\mathrm{b}} \times 100 \%
$$

Measurement of lysozyme was conducted according the method of Kafilzadeh (2013) which $10 \mu \mathrm{L}$ of plasma added into $190 \mu \mathrm{L}$ liquid suspension of Micrococcus lysodeicticus (Sigma) at $25^{\circ} \mathrm{C}$. The lysozyme activity can be formulated as follows:

Lysozyme activity $(\mathrm{UI} / \mathrm{mL} /$ minute $)=[(\mathrm{OD} 30 \mathrm{~s}-$ OD $30 \mathrm{~m}) \times 1,000] \times(1 /(\mathrm{t} \times \mathrm{p}))$

where: $\quad 1,000$ was conversion of the abso rbance (OD) into international units (UI),

t was time (minute), $p$ was plasma volume $(\mathrm{mL}), O D$ $30 \mathrm{~s}$ is optical density readings on 30 seconds, OD $30 \mathrm{~m}$ is optical density readings on 30 minutes

\section{Survival Rate (SR)}

$$
\mathrm{SR}(\%)=\frac{\mathrm{Nt}}{\mathrm{No}_{0}} \times 100 \%
$$

where: Nt was the number of live koi at the end of the observation, No was the number of koi in the initial observation

\section{Relative Percent Survival (RPS)}

$$
\text { RPS }=\left(1-\frac{\% \text { fish mortality of vaccinated }}{\% \text { Fish mortality of control }}\right) \times 100
$$

\section{Statistical Analysis}

Results are presented as Means \pm SD (standard deviation of means) and homogenic data was perform before analysis. The SPSS (Version, 20.0) programs were used for the statistical analyses. Oneway analysis of variance (One-way ANOVA) was used to determine whether there were any significant differences between treatments. If so, all treatments were further tested by Duncan Multiple Range Test (DMRT). All test were performed at the $95 \%$ confidence interval $(P \leq 0.05)$

\section{RESULTS AND DISCUSSIONS}

\section{Survival Rate}

Survival of fish among treatments were significantly different $(P<0.05)$. All fish in K-treatment (negative control) survived until the end of the study. This was in contrast with the treatment of $\mathrm{K}+$ (positive control) where at the end of the study fish alive only $15.55 \%$ Fish in treatment A (vaccine), B (vaccine + CFA), and $C$ (vaccine + IFA) successively survival of $68.88 \% 82.22 \%$ and $60.00 \%$ The highest survival was achieved by treatment $B$. Value of survival and relative survival were shown in Table 1.

\section{Relative Percent Survival}

While relative survival of both treatment $A$ and $C$ are not significantly different, but $A$ and $C$ significantly different with $B(P<0.05)$. The highest relative survival was achieved by treatment $B$, its the same thing with the achievements of the percentage of survival.

The survival of control fish were significantly different $(P<0.05)$ compared with other treatments (Table 1). It indicates that vaccination improved survival of fish. All fish in the negative control alive from the beginning to the end of the study, and unlike the case with the positive control, in which the remaining fish was only $15.55 \pm 3.84 \%$ The highest survival was achieved by treatment vaccination with the addition of Complete Freund's Adjuvant/CFA (treatment $B$ ), followed by vaccine treatment (treatment A) and then treated with additional vaccinations In- 
Table 1. Survival rate (SR) and relative percent survival (RPS) of fish during the study period of adjuvant and formalin inactivated vaccine against KHV in koi

\begin{tabular}{|c|c|c|c|c|c|}
\hline \multirow{2}{*}{ Parameter } & \multicolumn{5}{|c|}{ Treatments } \\
\hline & $\mathbf{K}+$ & K- & A & B & C \\
\hline SR (\%) & $15.55 \pm 3.84^{a}$ & $100.00 \pm 0.00^{\mathrm{e}}$ & $68.88 \pm 3.84^{c}$ & $82.22 \pm 3.84^{d}$ & $60.00 \pm 6.66^{b}$ \\
\hline RPS (\%) & $0^{a}$ & $100 \pm 0.00^{e}$ & $63.15 \pm 4.53^{c}$ & $78.94 \pm 4.55^{d}$ & $52.63 \pm 7.89^{e}$ \\
\hline Description: & $\begin{array}{l}\text { vaccined, + challan } \\
\text { th the addition of Co } \\
\text { and's Adjuvant (C). D } \\
\text { ta is expressed as M }\end{array}$ & $\begin{array}{l}\text { ged }(K+) \text {, no vaccine } \\
\text { omplete Freund's Adjuv } \\
\text { )ifferent superscript } \\
\text { lean } \pm \text { SD }\end{array}$ & $\begin{array}{l}d,+ \text { no challanged ( } \\
\text { lant (B), KHV vaccine } \\
\text { in the same row indi }\end{array}$ & $\begin{array}{l}\text { (K-), KHV vaccines (A) } \\
\text { with the addition of } \\
\text { icate significantly di }\end{array}$ & $\begin{array}{l}\text { 1), KHV vaccine } \\
\text { f Incomplete } \\
\text { lifferent }(P<0.05) \text {. }\end{array}$ \\
\hline
\end{tabular}

complete Freund's Adjuvant / IFA (treatment C). The addition of the adjuvant vaccine was found to further increase the survival of fish than just vaccine only. It is shown that $B$ was significantly different $(P<0.05)$ with $A$ and in accordance with the opinion of Kuby (2007), that the adjuvant is a substance when mixed with antigen then injected together will work to improve the immunogenicity of the antigen.

While the effectiveness of the vaccine protection can also be seen from the relative survival in Table 1. The highest survival was achieved by treatment $B$ followed treatment $A$ and $C$. The treatments $A$ was significantly different $(P<0.05)$ with $C$. RPS were obtained in the treatment of vaccination meet the range for effective protection in the process of vaccination unless treatment $\mathrm{C}(52.63 \pm 7.89 \%$. This is in line with Amend (1981) that for effective protection RPS suggested value of more than $60 \%$ Based on the results of this study it is not advisable to use $\mathrm{C}$ treatment because $\mathrm{C}$ does not meet the minimum limit the effectiveness of vaccine protection.

\section{ELISA Assay}

Vaccination aims to induce long-term immunity by stimulating specific components of the immune response is an antibody by inducing the formation of specific antibody. Figure 1 shows absorbance of vaccinated koi higher than the control. Before vaccination antibody titers tend to be similar and not significantly different $(P>0.05)$ among treatments. The

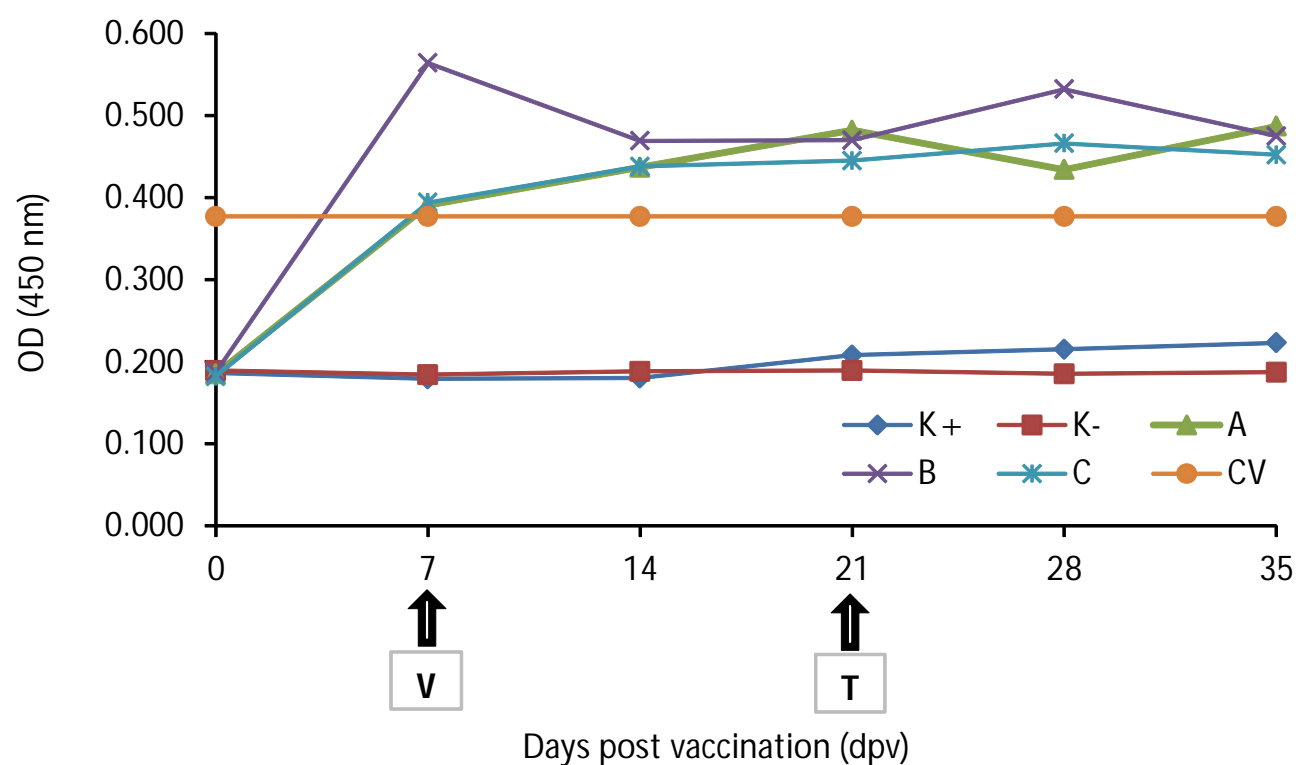

Figure 1. ELISA absorbances during the study period of adjuvant and formalin inactivated vaccine against KHV in koi. This test had been carried out using a monoclonal antibody. Description: no vaccined, challanged $(K+)$, no vaccined, no challanged (K-), vaccines (A), Complete Freund's Adjuvant vaccined (B), Incomplete Freund's Adjuvant vaccined (C), cut off value (CV), vaccination (V), challenge test $(\mathrm{T})$ 
cut off value (CV) or borderline positive value indicates the formation of protective antibodies against $\mathrm{KHV}$ obtained in this study at $0.377 \mathrm{~nm}$. Absorbance values of $\mathrm{K}+$ and $\mathrm{K}$ - during the study were below the $\mathrm{CV}$, indicates that no protective antibodies against KHV.

Positive anti-KHV antibodies formed in all treatments vaccination from 14 to $35 \mathrm{dpv}$. Anti-KHV antibodies begin to form at $7 \mathrm{dpv}$ namely in treatment $A$ and $C$ as indicated by intersect to the line CV (Figure 1). While on treatment $B$ had positive antibodies directly even reach the top of the formation of antibodies. This is presumably due to the effect of the vaccine and the addition of adjuvants in vaccines. Antibody formation is influenced by several factors such as temperature, dose of the vaccine, vaccine administration, the age, and weight of fish as well as the nature of the antigen (Ellis, 1988). The use of adjuvants capable of increasing the titer two times higher than without adjuvant (De Jong et al., 2003). In addition, adjuvants are also able to create a balance of humoral antibody response (Hunter, 2002). It shows that the inserted antigen be antigenic as capable of inducing an immune response to an increase in the value of antibody titers at vaccination treatment.

\section{Hematocrit Level}

Hematocrit level can be seen in Figure 2. Prior to vaccination and one week after vaccination there was no significant difference among treatments ( $P>0.05)$. At $14 \mathrm{dpv}$, there are significant differences $(P<0.05)$ between $\mathrm{K}+, \mathrm{K}-, \mathrm{C}$ with $\mathrm{A}$ and $\mathrm{B}$. The highest hematocrit levels achieved on day $21 \mathrm{dpv}$ in treatment $B$ and significantly different $(P<0.05)$ with other treatments. At $28 \mathrm{dpv}$ and $35 \mathrm{dpv}$ hematocrit levels decreased but treatment $B$ was the highest and significantly different with other treatments $(P<0.05)$.

Hematocrit is the percentage ratio between the solid red blood cells and plasma in the blood. Generally hematocrit before vaccination and one week after vaccination tend to be low and stable (Figure 2). Entering the second week (14 dpv) hematocrit of treatment $A$ and $B$ slightly higher and significantly different $(P<0.05)$ with the control and $C$. While the hematocrit reached the highest peak in the third week (21 dpv) is achieved by B. In normal conditions, hemato crit levels of carp ranged from 32\%to $43.8 \%$ (Radu, 2009). Shortly after the challenge test, hematocrit levels increased and then begin to decline until the end of the maintenance period. Decrease in hematocrit levels after challenge test showed that KHV infection that attacks fish is quite serious. Factors

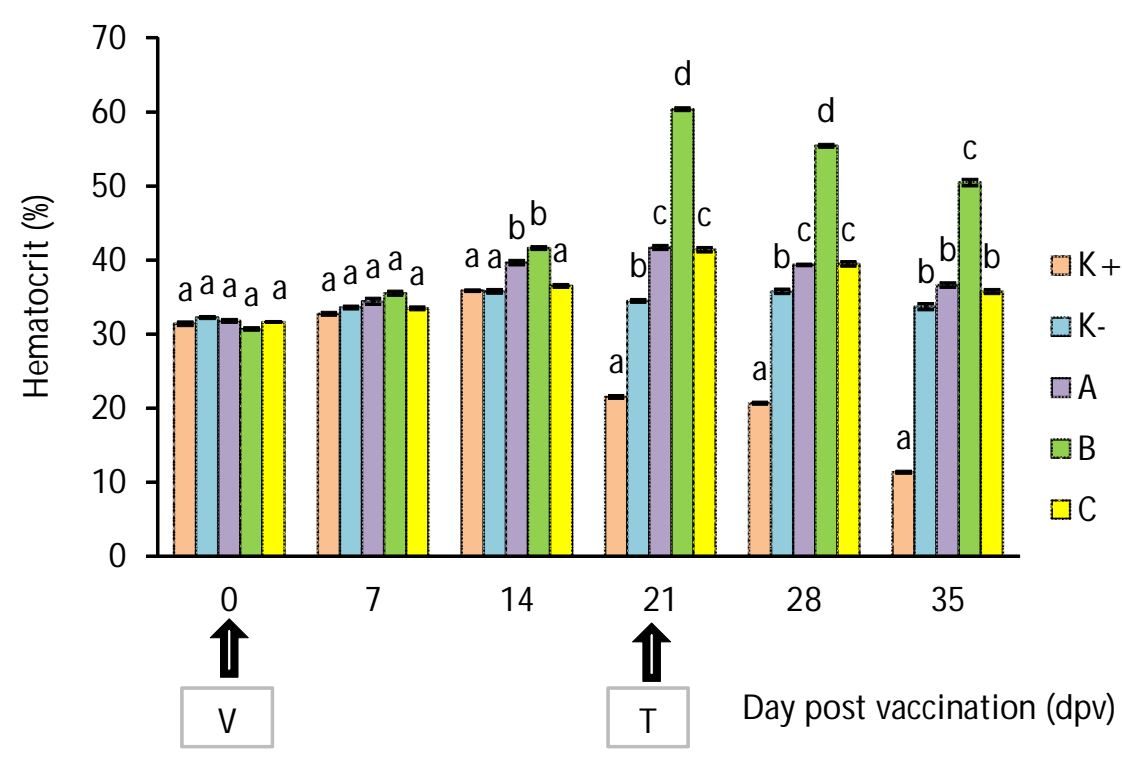

Figure 2. Hematocrit levels during the study period of adjuvant and formalin inactivated vaccine against KHV in koi. Description: no vaccined, challanged $(K+)$, no vaccined, no challanged $(K-)$, vaccines (A), Complete Freund's Adjuvant vaccined (B), Incomplete Freund's Adjuvant vaccined (C), vaccination (V), challenge test (T). Different superscript in the same group time indicate significantly different $(P<0.05)$. Data are expressed as Mean \pm SD 


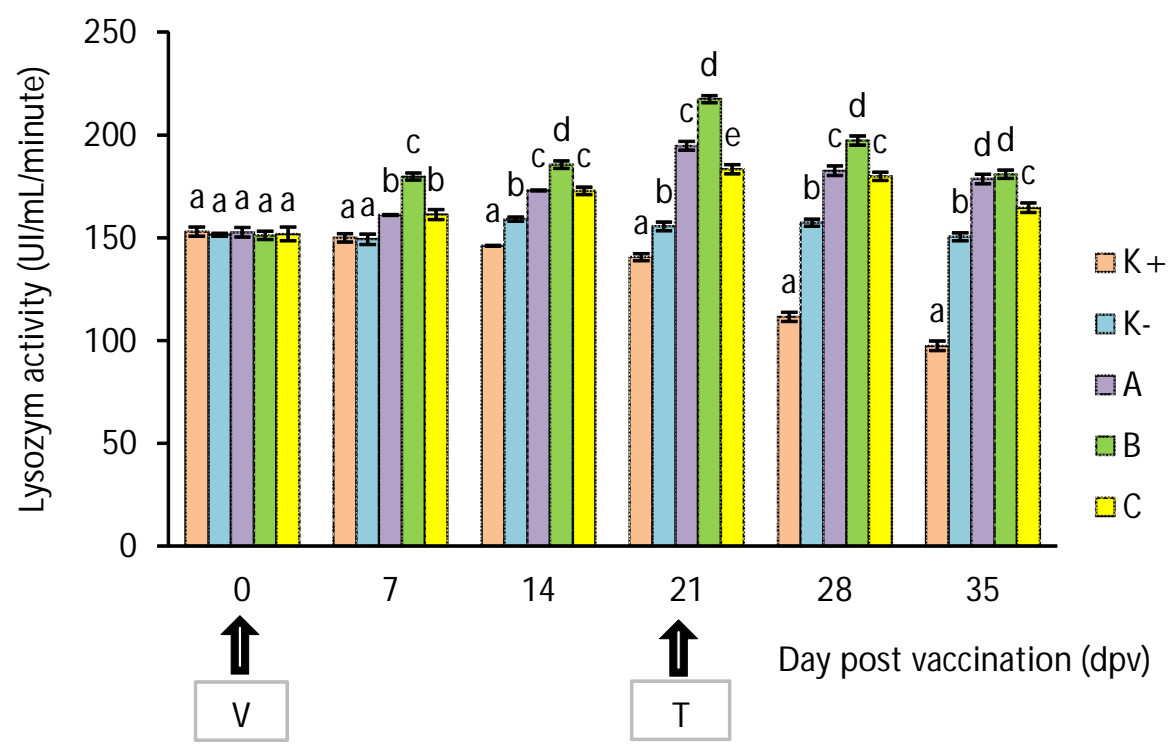

Figure 3. The activity of lysozyme during the study period of adjuvant and formalin inactivated vaccine against KHV in koi. Description: no vaccined, challanged $(K+)$, no vaccined, no challanged ( $K-)$, vaccines (A), Complete Freund's Adjuvant vaccined (B) + Incomplete Freund's Adjuvant vaccined (C), vaccination (V), challenge test $(T)$. Different superscript in the same group time indicate significantly different $(P<0.05)$. Data are expressed as Mean $\pm S D$

causing the decrease in hematocrit allegedly associated with a decrease in hemoglobin due KHV infection. This decrease was associated with hemorrhage in the base of the fin and bleeding in the brain.

\section{Lysozyme Activity}

Figure 3 shows lysozyme activity of fish. Before vaccination, the amount of lysozyme activity was not significantly different among treatments ( $P>0.05$ ). Lysozyme value of $\mathrm{K}+$ and $\mathrm{K}$ - is significantly different $(P<0.05)$ with $A$ and $C$ and also significantly different with the treatment $B$ on the $7 \mathrm{dpv}$. At $14 \mathrm{dpv}$ treatment $\mathrm{K}+$ and $\mathrm{K}$ - significantly different compared 21 $d p v$ the activity of lysozyme reached the highest peak in treatment $B$ and significantly different from other treatments. A week after the challenge test (28 dpv) each lysozyme activity decreased and continue to decrease till $35 \mathrm{dpv}$. Treatment B still shows higher but not significantly different with treatment $A$ $(P>0.05)$ and significantly different $(P<0.05)$ with $K+$, $\mathrm{K}-$, and $\mathrm{C}$.

Lysozyme is an important component in the defence system against pathogens. Lysozyme in fish can be detected from the serum, mucus, plasma, and organs such as gills and liver. Figure 3 shows the activity of lysozyme in general tends to increase after vaccination and tends to decrease after challenge test. Vaccination treatment can increase the activity of lysozyme and significantly different $(P<0.05)$ with the controls. Increased activity of this enzyme is also obtained in tilapia injected ECP Pseudomonas fluorescens (Attia et al., 2012). According Saurabh \& Sahoo (2008) lysozyme is a distributed hydrolase, and plays an important role in the biological defense system. This enzyme has antiviral, antibacterial and anti-inflammatory properties. In addition, increase lysozyme activity closely associated with humoral factors that can increase phagocytic activity in fish (Veersamy et al., 2014).

On the positive control $(\mathrm{K}+)$ is very clearly visible decrease in the activity of lysozyme after challenge test. Lysozyme in fish is an indicator of nonspecific immune response to the invasion of antigens. Lysozyme is the first layer of defense mechanism that is very important for fish to fight pathogens (Saurabh \& Sahoo, 2008). Lysozyme can increase phagocytic activity is as opsonin or directly activate neutrophils and macrophages (Bhagwat et al., 2010). 


\section{CONCLUSION}

The application of inactivated vaccine with the addition of Complete Freund's Adjuvant resulted the highest survival and enhancement of the immune response in koi (C. carpio) against KHV infection.

\section{ACKNOWLEDGMENT}

Thanks to the Ministry of Marine Affairs and Fisheries Republic of Indonesia for providing partial funding of the study, thanks to Research and Development Institute for Ornamental Fish Culture, Depok for supporting research, and also thanks to Research Station for Fish Disease Control for allowing to work in the laboratory.

\section{REFERENCES}

Antychowicz, J., Matras, M., Bergmann S.M., \& Haenen, O. (2005). Epidemiology, pathogenicity and molecular biology of Koi Herpesvirus isolated in Poland. Veterinary Research, 40, 367-373.

Amen, D.F. (1981). Potency testing of fish vaccines. Developments in Biological Standardization, 49, 447454.

Attia, A., Mesalhy, S., Galil, Y.A., \& Fathi, M. (2012). Effect of injection vaccination against Pseudomonas fluorescent on specific and non-specific immune response of nile tilapia (Oreochromis niloticus) using different prepared antigens. DOI: 10.4172/ scientificreports.552. Scientific Reports, 1(12), 1-7.

Aucouturier, J., Dupuis, L., \& Ganne, V. (2001). Adjuvants designed for veterinary and human vaccines. Vaccine, 19, 2666-2672.

Bhagwat, D.P., Kharya, M.D., Bani, S., Kaul, A., Kour, K., Chauhan, P.S., Suri, K.A., \& Satti, N.K. (2010). Immunosuppressive properties of Pluchea lanceolata leaves. Indian Journal of Pharmacology, 42(1), 21-26.

De Jong, J.C., Palache, A.M., Beyer, W.E., Rimmelzwaan, G.F., Boon, A.C., \& Osterhaus, A.D.M.E. (2003). Haemagglutination - inhibiting antibody to influenza virus. Developmental Biology, $115,63-73$.

Ellis, A.E. (1988). General principles of fish vaccination. In Ellis, A.-E. (Ed.). Academic Press. London. Fish Vaccination, p. 1-19.

Hunter, R.L. (2002). Overview of vaccine adjuvants: Present and future. Vaccine, 20, 7-12.

Ilouze, M., Dishon, A., Kahan, T., \& Kotler, M. (2006). Cyprinid Herpes Virus-3 (CyHV-3) bears genes of genetically distant large DNA viruses. FEBS Letters, 580, 4473-4478.

Kafilzadeh, R., Mousavi, S.M., \& Baboli, M.J. (2013). Effects of Saccharomyces cerevisiae
(Saccharomycetes: Saccharomycetaceae) on Astronotus ocellatus as growth promoter and immuno stimulant. AACL Bioflux, 6(6), 587-598.

Kuby (2007). Immunology. $6^{\text {th }}$ ed. W.H. Freeman and Company. New York. US, 574 pp.

Lio-Po, G.D. (2011). Recent development in the study and surveilence of Koi Herpesvirus (KHV) in Asia. In Bondad-Reantaso, M.G., Jones, J.B., Corsin, F., \& Aoki, T. (Eds.). Disease in Asian Aquaculture VII. Fish Health Section, Asian Fisheries Society, Selangor, Malaysia.

Melba, G.B.R. (2004). Trans-boundary Aquatic Animal Diseases: Focus on Koi Herpesvirus (KHV). Aquaculture Asia, 9, 24-28.

Nakajima, K., Maeno, Y., Honda, A., Yokoyama, K., Tooriyama, T., \& M anabe, S. (1999). Effectiveness of a vaccine against red sea bream iridoviral disease in a field trial test. Disease of Aquatic Organisms, 36, 73-75.

Perelberg, A., Smirnov, M., Hutoran, M., Diamant, A., Bejerano, T., \& Kotler, M. (2003). Epidemiological description of new viral desease afflicting cultured Cyprinus carpio in Israel. Israeli Journal Aquatic, 55, 5-12.

Radu, D., Oprea, L., Bucur, C., Costache, M., \& Oprea, D. (2009). Characteristics of haematological parameters for carp culture and koi (Cyprinus carpio) reared in an intensive system. Bull. UASVM Animal Sci. Biotech., 66(1-2), 336-342.

Reed, L.J., \& Muench, H. (1938). A simple method of estimating fifty percent endpoints. American Journal Hygene, 27, 493-497.

Ronen, A., Perelberg, A., Abramowitz, J., Hutoran, M., Tinman, S., Bejerano, I., Steinitz, M., \& Kotler, $M$. (2003). Efficient vaccine against the virus causing a lethal disease in cultured Cyprinus carpio. Vaccine, 21, 4677-4684.

Saurabh, S., \& Sahoo, P.K. (2008). Lysozyme: an important defence molecule of fish innate immune system. Aquaculture research, 39, 223-239.

Sunarto, A., Rukyani, A., \& Itami, T. (2005). Indonesian experience on the outbreak of Koi Herpesvirus in koi and carp (Cyprinus caprio). Bull. Fish. Res. Agen. Suplement., 2, 15-21.

Veersamy, R., Min, L.S., Mohanraj, Pauline, R., Sivadasan, S., Varghese, C., Rajak, H., \& Marimuthu, K. (2014). Effect of aqueous extract of Polygonum minus leaf on the immunity and survival of African catfish (Clarias gariepinus). Journal of Coastlife M edicine, 2(3), 209-213.

Yasumoto, S., Kuzuya, Y., Yoshimura, Y., \& Miyazaki, T. (2006). Oral immunization of common carp with a liposome vaccine fusing Koi Herpesvirus antigen. Fish Pathology, 41, 141-145. 